\title{
PROMOTERS OF ARTIFICIAL INTELLIGENCE CAPABILITY IN THE NIGERIAN TELECOMMUNICATIONS INDUSTRY
}

\begin{tabular}{|c|c|}
\hline 1 Waribugo Sylva & $\begin{array}{c}{ }^{1} \text { Faculty of Management Sciences, } \\
\text { University of Port Harcourt, Nigeria }\end{array}$ \\
\hline${ }^{2}$ Onyekachi Chinedu Scott & $\begin{array}{c}{ }^{2} \text { University of Port Harcourt Business } \\
\text { School, Port Harcourt, Nigeria }\end{array}$ \\
\hline
\end{tabular}

\section{ABSTRACT}

The rise of Big Data, coupled with the need for organisations to catch up with the dynamic and complex business environment, has sparked a new wave of interest in the field of Artificial Intelligence (AI). This study investigated vendor partnership and managerial support as enhancers of artificial intelligence capability of telecommunication firms in Nigeria, using competitive pressure as a moderator. A survey was conducted among 141 managers and IT staff from four dominant telecommunication firms, and data were analysed to generate descriptive outputs, with the aid of the Statistical Package for Social Sciences (SPSS) version 27. Moreover, five hypotheses were tested using the Partial Least Squares Structural Equation Modelling, with the aid of SmartPLS 3.2.9. Inferential output indicates that higher levels of vendor partnership and managerial support amplify artificial intelligence capability, while competitive pressure neither promotes artificial intelligence capability nor buffers the relationship between each of the two exogenous variables and artificial intelligence capability. The study recommends that telecommunication companies should only select partners who are trusted, reliable and knowledgeable in emerging AI- enabled technologies, and emphasize lasting, strong and extensive social, economic, commercial and technical ties. Also, managers should nurture a culture that enables members adapt to new technologies; and channel resources to adequately fund AI-initiatives.

KEYWORDS: Artificial Intelligence Capability, Managerial Support, Vendor Partnership, Competitive Pressure.

\section{0: INTRODUCTION}

The incredible speed with which Artificial Intelligence (AI) is entering every sector is forcing companies to get into the race to make their company an AI company (Park, 2017). This is also compelling business, experts, pioneers, entrepreneurs and investigators to use AI to design new strategies and create new sources of business value (Klosters, 2016). Primarily, the advancement in AI is the heart of the enhanced performance of all other technologies and the evolution of Industry 4.0. This technological advancement, attributed to AI, would facilitate human-to-machine interactions, change the logic of business models, and transform the lifestyle and living standards of the human. In fact,the advent of new data-driven technologies spurred by automation and developments in artificial intelligence (AI) is promising significant disruption to long-established practices (Brooks, Gherhes \& Vorley, 2020).

Through AI capability, organisations orchestrate resources and apply computer systems able to engage in human-like processes such as learning, reasoning, and self-correction towards 
business tasks. This leads to business value creation via mechanisms such as product design, automation, quality control and smart maintenance. Moreover, AI capability enhances decision support and business innovation. Particularly, it reflects the ability of an AI system to help managers and employees sense external stimuli and assist in decision-making by enabling analysis and offering advice and implementation support (Seshadri, 1996).

In the telecommunications sector, higher level of AI capability is known to promote the operations and maintenance of telecom networks and services (Macleish, 1988; Muller et al., 1993). Moreover, the emergence of the complex 5G network - with its complex and distributed nodes, and dense small cells spectrum - has brought about the need for telecom organisations to embrace $\mathrm{AI}$ in order to manage and maintain such a complex network (Xu, 2011; Xu, \& Duan, 2018). How to use the powerful analysis, judgment, prediction and other capabilities provided by $\mathrm{AI}$ algorithms has become an important topic for the telecom industry.

Chen (2019) identified vendor partnership, managerial support and competitive pressure as variables that could influence the ability of a firm to orchestrate organizational resources and apply computer systems able to engage in human-like processes such as learning, reasoning, and selfcorrection towards business tasks.

Vendor partnership is a long term strategic coalition between a firm and its vendor(s) that creates core value through activities such as research, product development, manufacturing, marketing, sales, and distribution, with the objective of increasing benefits to all partners by reducing total cost of acquisition, possession, and disposal of goods and services (Maheshwari et al., 2006, Li et al., 2006). Healthy partnership is built on mutual trust and provides added value not only to both partners but also to end customers. It reduces inventory levels, and enhances supply chain as well as firm's performance.

Thus, AI capability in firms is usually associated with IT vendors and collaborative partners because many firms are unfamiliar with AI technologies. Furthermore, vendor involvement can significantly contribute to the rate of adoption of new technology, diffusion of new products and innovation (Assael, 1984; Sulaiman, \& Wickramasinghe, 2014).

Managerial support occurs when managers treat employees fairly, build trust and consult employees regarding work matters so they can build a relationship of mutual respect, where employees perceive that their needs are considered and are acted on appropriately (Eisenberger, Stinglhamber, Vandenberghe, Sucharski \& Rhoades, 2002). Such support can also facilitate the communication and implementation of strategic decisions (Dasgupta, 2015). Managerial support influences the general attitude towards change (Svimez, 2003).
Moreover, the adoption of AI in an organization depends on the general receptivity towards change held by the organization's members (Dewar \& Dutton 1986). Common logic, therefore, suggests that support from managers on the adoption of AI is a critical component of AI capability. Such support is reflected by the general policies and strategies of an organization toward its environments, like technology sensitivity, resistance to change, attitude toward risk and openness to external information (Stonehouse \& Pemberton, 2002). Furthermore, managerial support is a critical factor of commitment from managers that guides the allocation of resources and the integration of services (Müller \& Jugdev, 2012). It facilitates effective implementation of technology and project success (Elbanna, 2013).

Furthermore, competitive pressure is a driving force for process, product and technological innovation or efficiency (Liebenstein, 1966; Vives, 2008), which is a strategic necessity to compete in the marketplace (Lippert \& Govindarajulu, 2006). Moreover, Mansfield et al. (1977) and Gibbs and Kraemer (2004) find that fierce competition stimulates the rapid diffusion of IT innovations. In the same vein, Oliveira and Martins (2008) submit that firms feel pressure if their competitors adopt certain new technologies. They tend to adopt these technologies to immediately improve their capabilities and maintain their competitiveness. Thus, common logic suggests that competitive pressures will make companies adopt new AI technologies or improve existing capabilities to improve their products and services in the competitive business environment. Competitive pressure could make firm's to spend more resources toward developing new technology and then deterring new entrants.

Some research has been conducted on AI as new wave of technological advancement, which serves as both a catalyst of and a tool for transformation, providing firm with significant opportunities to learn from, and adapt to, their external environment in order to remain competitive. Specifically, studies in AI have been conducted in engineering (Pham, et al.1999), science (Cartwright, 1997), education (Lajoie \& Vivet, 2002), medicine (Ramesh, et al. 2004), business, accounting, finance, marketing, economics, and law (Rauch-Hindin, 1986). It is already being applied to such endeavours as the self-driving car, healthcare, and new media (Bollier, 2017). However, while there have been significant reports of AI in the literature (e.g., Fernald \& Jones, 2014; Purdy \& Daugherty, 2016; Aghion, et al., 2017) this has not been the case for enhancers of AI capabilities in telecommunications sector of developing countries such as Nigeria.

Moreover, the few empirical studies on AI that are closely related to AI capability bother only on AI adoption (e.g., Aboelmaged, 2014; Chen, 2019). This paper argues that the adoption of AI itself does not reveal the ability of the organisation to catch 
up with exogenous market demands through sensing, comprehension, learning, acting and adaption, in order to remain competitive. Thus, this study bridges the gap in literature by investigation the influence of two organisational variables (vendor partnership and managerial support) and one external factor (competitive pressure) on AI capabilities of telecommunication companies in Nigeria.

\section{Problem Statement}

The Nigerian telecommunications sector was liberalized when the Nigerian Communication Commission (NCC) granted licenses to five Global System for Mobile Communication (GSM) service providers - Econet, MTN, MTel, Globacom and Etisalat- between 1999 and 2008.

In terms of growth, statistics show that Nigeria has experienced phenomenal Compound annual growth rate (CAGR) in the telecommunications sector at $31.8 \%$ between 2000 and 2019. Moreover, from a negligible $0.1 \%$ contribution to GDP in 1999, prior to the adoption of GSM, the sector's contribution to GDP has risen to $10.9 \%$ in $Q_{1}$ of 2020 , with nominal GDP rising from $\mathrm{N} 26.3 \mathrm{bn}$ to N7.4tn. Interestingly, the sector has been the fastest growing at a normalized average (excluding 2000 - 2001) of $34.9 \%$ between 2000 and 2010 before moderating to an average growth of $4.6 \%$ from 2011 to 2019 . The sector has also been one of the most resilient, with growth averaging $6.9 \%$ between 2017 and 2019 while also being one of the most important, with an outsized contribution to the economy's growth since the 2016 recession. As at $Q_{1}$ of 2020, the telecommunication sector has a GDP larger than that of the oil sector $(9.5 \%)$.

Apart from promoting and enhancing trade between Nigeria and her international partners, the sector also plays an important role in connecting various sectors of the nation's economy, such as insurance, IT, banking, consultancies, shipping, Small and Medium Scale Enterprises, in order to achieve mutual goals. Furthermore, mobile internet subscribers in Nigeria have increased from 2.3 million in January 2002 to 128.4 million in January 2020.

Notwithstanding the remarkable credentials of the telecommunication industry in Nigeria, there is widespread dissatisfaction among consumers with respect to the endemic poor services of the telecommunication companies (Sylva, \& Akpan, 2016; Ibekwe, et al., 2019). There are intolerably frequent incidences of multiple call attempts, call completion before the communicating parties are ready to end the call; there are also glitches with financial services that relied on interconnection such as cash withdrawal from Automated Teller Machines and making payments using electronic point of sale machines.
It is no news that there are insufficient interconnection circuits amongst the operators. Also, operators have insufficient capacities and persistently experience "major systems failure" and find it difficult to integrate signals between the different network components supplied by different vendors for a particular mobile company. Operators continued to fall short of the published Key Performance Indicators (KPIs) contained in draft regulations.

With the expansion of the network scale, the development of business types and the emergence of the digital transformation, the telecom industry constantly face new challenges. On the one hand, the demand for speedier data connectivity, higher resolution, quicker video streaming, and ample multimedia applications keeps growing (Castro, Richart, Baliosian, \& Grampín, 2018; Akpan, Ibekwe, Worgu, \& Nwangwu, 2018). On the other hand, threats from fast and highly efficient web-scale companies are getting stronger. These challenges push telecom operators to grow their subscriber bases by offering improved services and new features.

Brooks, Gherhes and Vorley (2020) argue that $\mathrm{AI}$ is an innovative technology that holds the promise of transforming services sectors. Following this, one of the key trends that could make the telecoms industry to meet their challenges is the deployment of the transformative power of artificial intelligence (AI). Beyond this, telecom firms may need to improve the capability of their AI infrastructure to catch up with exogenous market demands through sensing, comprehension, learning, acting and adaption, in order to remain competitive.

Given the importance of AI, it is crucial to understand the interactive relationship between AI capability and its determinants as perceived by those working in the sector. This is particularly important for telecommunication companies which operate in a highly competitive business environment. In this regard, Chen (2019), identified compatibility, relative advantage, complexity, managerial support, government involvement, and vendor partnership as factors that influence the adoption of artificial intelligence in Chinese firms. Moreover, Aboelmaged (2014) submit that competitive pressure makes firms to adopt new technologies geared toward improving capabilities and mitigating threats.

Based on the foregoing, this study investigates the hypothesized relationship between AI and three exogenous variables, namely: vendor partnership, managerial support and competitive pressure. The Nigerian telecommunication industry is the subject of investigation.

\section{Conceptual Framework of the Study}

Based on the foregoing, a conceptual framework is developed as shown below: 


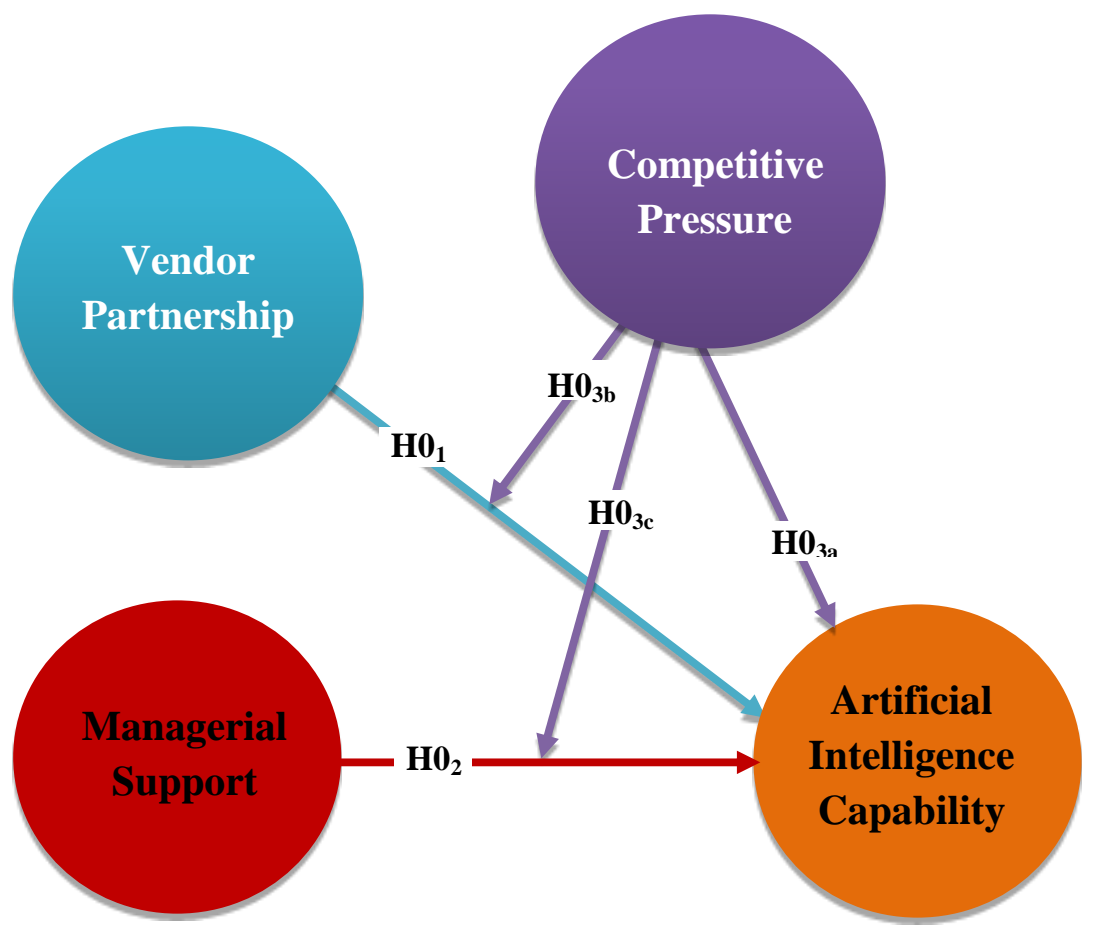

Figure 1: Conceptual framework

Source: Vendor partnership and Managerial support as predictors; Artificial Intelligence Capability as criterion variable; Competitive pressure as moderator (Aboelmaged ,2014; Chen, 2019).

Figure 1.1 indicates that vendor partnership and managerial support are the exogenous variables; artificial intelligence capability is the endogenous variable; while competitive pressure is the moderator.

The following hypotheses are hereby formulated for the study:

Ho1 $_{\text {: }} \quad$ There is no significant relationship between vendor partnership and artificial intelligence capability.

$\mathrm{H}_{\mathrm{O} 2}$ : There is no significant relationship between managerial support and artificial intelligence capability.

$\mathbf{H}_{3 \mathrm{a}}$ : There is no significant relationship between competitive pressure and artificial intelligence capability.

$\mathbf{H}_{3 \mathrm{~b}}$ : Variation in artificial intelligence capability due to vendor partnership is not significantly a function of competitive pressure.

$\mathbf{H}_{3 \mathbf{c}}$ : Variation in artificial intelligence capability due to managerial support is not significantly a function of competitive pressure.

\section{LITERATURE REVIEW}

\subsection{Baseline Theory}

\subsubsection{Technology-Organization-} Environment (TOE) Framework

Popularly referred to as Tornatzky and Fleischer's (1990) framework, the TechnologyOrganization-Environment model (DePietro et al.,
1990) comprehensively explains the likelihood of a particular firm adopting and utilizing innovations based on technological, organizational, environmental, and socio-cultural factors. The TOE framework suggests that these three factors influence the choice of organisations to embrace technological innovation, thereby collectively dictation the manner in which companies adopt new technology or improve their technological capabilities (Baker, 2012). The technological context includes the characteristics and the usefulness of the innovative technology, the organization context contains the internal issues within the company such as management, employees, products and services; and the environmental context involves the issues exist in the business related field, such as the competitors and business partners (Chatterjee, Grewal, \& Sambamurthy, 2002).

The inclusion of technological, organizational and environmental variables has made TOE advantageous over other adoption models in studying technology adoption, technology capability and value creation from technology innovation (Hossain \& Quaddus, 2011; Ramdani et al., 2009; Zhu \& Kraemer, 2005). Also, it is free from industry- and firm-size restrictions (Wen \& Chen, 2010). Hence, it provides a holistic picture for users of technology, foreseeing challenges, factors influencing business innovation-adoption decisions and to develop better organizational capabilities using the technology (Wang et al., 2010). 
Finally, the TOE Model is considered appropriate as a baseline theory because AI capability is an offshoot of the adoption of innovative technology. Moreover, the organisational context involving management and employees underscores the need for top managers to provide support for employees in the allocation resources, the integration of services, and the re-engineering of processes to enhance AI capabilities (Hsu \& Yeh, 2016). Furthermore, the environmental factor "competitors" suggests that firms opt for improvement in technological capabilities when they experience competitive pressure (Rosas et al., 2017). Thus, an organization that fails to grow its capabilities will be less competitive and cascade towards extinction (Taneja et al., 2016).

\subsection{Conceptual Review}

\subsubsection{Artificial Intelligence}

Artificial Intelligence (AI), as a term, was introduced into scholarly literature in 1956 by Marvin Minsky and John McCarthy (a computer scientist at Stanford), who hosted the approximately two-month Dartmouth Summer Research Project on Artificial Intelligence (DSRPAI) at Dartmouth College in New Hampshire. According to Minsky, "AI is the science of making machines capable of performing tasks that would require intelligence if done by humans" (p. 6). Similarly, AI is defined as "the science and engineering of making intelligent machines, especially intelligent computer programs" (McCarthy, 2007, p.2). AI is also viewed as "a system's ability to interpret external data correctly, to learn from such data, and to use those learning to achieve specific goals and tasks through flexible adaptation" (Kaplan \& Haenlein, 2019, p. 15).

Thus, AI has to do with the use of autonomous thinking machines that are free of human control in organisations. In order words, it is a set of technologies that simulate human cognitive processes, including reasoning, learning, and selfcorrection. It is the application of knowledge, thought, and learning, to computer systems to aid humans. AI technology is built into machines that work with their own developed programming language, which manipulate knowledge more effectively.

Unlike conventional programming, artificial intelligence programs manipulate predominantly qualitative rather than numeric information. These programs use declarative knowledge, i.e. assertions whose truth-value is independent of the algorithmic context. In addition, AI programs can induce, deduct and sometimes guess data, as well as reconsider decisions by employing back tracking for solutions. Thus, AI is an expert system that uses natural language processing mechanism and vision, geared toward heuristic problem solving. Essentially, AI is an enabling technology or general-purpose technology which is increasingly prompting companies to identify new ways of creating, delivering and capturing value from their business activities.

Qi, Wu, Li and Shu (2007) submit that AI comprises Expert Systems (ES), Natural language understanding (NLU), Machine learning (ML), Distributed artificial intelligence (DAI) and Robotics. An ES is a computer program that encodes human expertise. Natural language understanding (NLU) includes natural language processing, speech recognition and speech synthesis. The intent of natural language processing is to develop a language interface for computer systems to process inputs and outputs in different languages. Speech recognition is the processing and interpretation of human voice. Speech synthesis is the computer generation of humanlike speech.

Machine learning (ML) involves the use of neural networks and genetic algorithms to make changes in work methods so that the same work can be done more efficiently than previously. Distributed Artificial Intelligence (DAI) attempts to solve problems in a distributed manner. A DAI system consists of a society of agents; each agent is in charge of a subpart of the problem. Different levels of communication, cooperation and control among the agents might be necessary in order to achieve a coherent global solution (Tang et al., 2001). Robotics focuses on using devices for controlled motion. Robotics is the art of controlling machine movements with computers (Xu, 2000).

\subsubsection{Artificial Intelligence and the Telecommunication Industry}

Following the pressures of globalisation and the need to adopt new technologies to create better socio-economic value, the government of Nigeria fully liberalised the telecommunication industry in 1999. GSM licenses were given to ECONET WIRELESS and MTN in 2001. NITEL, which had licence the same year, could not provide services mainly due to its poor strategic fit. Moreover, the surge in dealership and subscription prompted the Nigerian Communications Commission to issue another licence to GLOBACOM in 2002, while ETISALAT was launched in 2008. Due to political shenanigans, mismanagement and lack of dynamic capabilities, ECONET WIRELESS changed its name several times - from Vodacom, Vmobile, Celtel and Zain, to present AIRTEL. Also ETISALAT has changed to 9MOBILE. Currently, the telecoms market is mainly oligopolistic, dominated by MTNN, AIRTEL, GLOBACOM and 9MOBILE.

Since the introduction of GSM, the Nigerian telecom industry has gone through a series of incremental innovation driven by artificial intelligence. The AI component in telecommunication operations involves expert systems (Macleish, 1988; Qi, et al., 2007) that diagnose complex equipment in an off-line mode. Moreover, AI platforms are deployed to improve the operations and maintenance of telecom networks and services (Seshadri, 1996). Since these early 
applications, more and more AI techniques have been applied to telecommunications. Expert systems of AI are suitable for fault detection, network monitoring, diagnosing, controlling and resource configuration. They are used as intelligent controllers for multiple access mobile cellular telecommunications systems and design optical fibre communication links (Dabke et al., 1995).

Furthermore, AI-statistical tree growing algorithm is used to identify the operations area where improvements are expected to affect the customer most. Through a Distributed Artificial Intelligence (DAI), agent-oriented middleware architectures are introduced for network and service management in telecommunications. Also, AI helps telecommunication firms to provide the requested services using the allocated equipment. Agent-based routing algorithms are provided to realize adaptive and efficient utilization of network resources in response to changes in the network catering for load balancing and fault management (Wedde \& Farooq, 2006).

According to Qi, Wu, Li and Shu (2007), the principal functions of $\mathrm{AI}$ in the telecommunication industry are: fault- and fraud detection, performance analysis and network monitoring, network controlling (e.g., root-tracing of alarm), network resource configuration, multi-services management and deployment suggestion, network resource management and optimization, and automatic correction. Telecommunication firms also use AI and machine learning to extract meaningful business insights from customer data, so they can make faster and better business decisions. This crunching of the data by AI helps with customer segmentation, customer churn prevention, prediction of the lifetime value of the customer, product development, improving margins, price optimization, and more. Telecom services such as voice assistant, smart speaker and chatbots are products of AI.

Currently, China Mobile uses NovoNet, an AI platform for Intelligent Quality Inspection System; AT\&T deploys Threat Intellect platform for network security and AI chatbot for contract center; Verizone uses Network stability surveillance in the fiber optic broadband service; Orange uses AI research project to predict demand patterns in $5 \mathrm{G}$ networks, among other global telecom companies that deploy AI.

In addition, the significance of $\mathrm{AI}$ in the telecommunications industry is underscored by the fact that the telecommunications environment has continuous distribution and expansion in network size, with strict fault-tolerance requirements. Artificial systems in telecommunications have to cope with a great variety of telecommunication protocols, and numerous hardware platforms and network architectures (Csele'nyi et al., 1998). Nowadays, factors such as globalization and technology innovation offer further challenges to telecommunication operations, and the industry must become more and more competitive in order to survive in a global market (Zhang et al., 2004; Wang $\&$ Archer, 2007), with many more competitors and pressures for increased customer choice, lower price and improved service quality.

The Internet of Things (IoT) and 5G networks are important roadmaps for the development of current telecom networks, and the implementation of each technology will bring about major changes to the current network architecture and technology (Zhang \& Lorenz, 2018). At the same time, there will be huge challenges in the design, operation, and maintenance of the telecom network.

The key issue for telecom operators in Nigeria is how to manage and operate the dizzyingly complex next generation 5G/Internet of Things (IoT) networks. The $5 \mathrm{G}$ network is rather complex because it consists of various distributed nodes, dense small cells, millimeter waves, unlicensed spectrum, shared spectrum, and $3 \mathrm{G} / 4 \mathrm{G}$ derivative technologies $(\mathrm{Xu}$, 2011; Xu, \& Duan, 2018).

Only AI can manage and maintain such a complex network. AI with robust data analysis and information extraction capabilities brings new opportunities to telecom networks. As the infrastructure of information communication, telecom networks have enormous space and potential for applying AI technology. How to use the powerful analysis, judgment, prediction and other capabilities provided by AI algorithms to enhance the application of network elements and business systems, and combine AI with the design, construction, maintenance, operation and optimization of telecommunication networks has become an important topic for the telecom industry (Xinhua, 2016)

\subsubsection{Artificial Intelligence Capability}

Artificial Intelligence Capability comprises the structures, strategies and processes put in place by organisations to effectively utilize the AI infrastructure through design, construction, maintenance, operation, judgement, prediction and optimization (Xinhua, 2016). According to Bataller and Harris (2018), AI capability is the ability to sense, comprehend, act, and learn in the process of operating in an $\mathrm{AI}$ environment.

Particularly, a firm that has acquired capability in AI easily perceives its environment by acquiring data like images, speech, and text; can easily recognise, interpret and contextualise patterns to derive their true meanings; take actions based on their comprehension of the physical or digital world; and continuously optimize its performance by learning from the success or failure of those actions Adadi et al. 2019).

It is the AI capabilities that gives meaning to any AI artefact is the organisation (Bowen \& Morosan 2018). Scholars (e.g., Ghahramani 2015; Huang \& Rust, 2018) argue that in an AI-enhanced system, the input is enhanced by sense, processing by comprehend, output by act, and feedback by learn. Therefore, organizing AI research is based on how 
organisations build and unleash these key capabilities as they pass through various stages of digital transformation and "interpret external data correctly, learn from such data, and exhibit flexible adaptation" (Kaplan \& Haenlein, 2019, p. 17) in order to remain competitive.

\subsubsection{Vendor Partnership}

Vendor partnership is the a long term collaboration between two or more firms in a supply chain which facilitates the creating of mutual benefits or value through research, product development, manufacturing, marketing, sales, and distribution $(\mathrm{Li}$ et al., 2006). Partnerships are forged to promote operational capabilities of participating organizations and to help them achieve significant on-going benefits (Stuart, 1997). Moreover, strong partnership with vendors facilitates open communications and helps organisations to have deeper understanding of changing technologies in order to stay abreast of industry trends. Moreover, vendors can also mount pressure on their partners to implement and adopt a new technology. Support from vendors ensures effective implementation, market acceptance and value maximization of technologies (Teo, et al., 2009).

In the deployment of AI, business (trading) partners relate to the AI infrastructure vendors. Organizations, regardless of size, rely on the experience and skills of business partners or vendors when looking to adopt AI services. Vendors' previous history on IT projects affects the decision of whether to adopt a new technology or improve on existing technological capabilities. Vendors in the telecom sector (e.g., Proxim, Radwin, Ubiquity, Cambium, Ligowave, Cisco, D-Link, MikroTik, Netgear), build scalable networking software/ hardware, broadband wireless networking systems for communities, enterprises, governments, and service providers. They offer wireless LAN, point-tomultipoint and point-to-point products through a channel network and other high-technology services.

Organizations that utilize AI are concerned about the ability of service vendors to readily replace resources, provide complementary technologies and ensure the availability of data when needed. To ensure the desired level of availability, service level agreements and a combination of precautionary measures can be used. Keeping in mind the complex architecture of AI, and considering the fact that telecommunication firms do not have all the technical and transformational skills in-house for managing innovations, such as AI, the development of their AI capabilities may require tighter integration of business partners and suppliers (Wang et al., 2010).

\subsubsection{Managerial Support}

Managerial support reflects, in many ways, the importance top management place on AI-enabled systems (Byrd \& Davidson, 2003). Support and commitment from managers is a critical factor in any major organizational change because it guides the allocation of resources and the integration of services
(Co et al., 1998). Managers that understand company culture and values, and what is good and promote the growth of technological capabilities (Martin Rojas et al. 2011) by observing and talking to employees, recognising obstacles, problems and success, and encouraging teams and cross-functional cooperation and communication in the use of AI-enabled platforms (Garcia Rodriguez et al. 2008).

Managerial support also involves economic investment in acquiring new AI domains, as well as greater involvement in the learning of these AI technologies (Bolivar Ramos et al. 2012; Martin Rojas et al. 2011). Management support for technologies enables the organisation to access, transmit, and use information regarding the technology (Carlsson \& El Sawy 2008; Lin 2007; Martin Rojas et al. 2011) by nurturing an environment more favourable to the acceptance and use of the technology. Furthermore, the employees of firms that implement a technology-supportive culture are likely to have more precise knowledge of the organisational objectives for innovation and will make a greater effort to achieve these objectives more efficiently (Martin Rojas et al. 2011).

\subsubsection{Competitive Pressure}

Competitive pressure is the extent of coercion that the company feels from competitors within the industry (Zhu \& Kraemer, 2005). Competitive pressure is viewed in economics in terms of its effect on a firm's incentives to undertake product and process innovations. The result of product innovation is the introduction of a new product or technology into the market. Hence the incentive for the introduction of a new technology is determined by the profit level associated with it, which leads to a reduction in a firm's cost level (Boone, 2000).

Moreover, the main reason telecommunication firms adopt technologies, such as AI-enabled systems, is to enhance their profits and competitiveness (Pollard \& Hayne, 1998). Therefore, telecommunication firms may feel the pressure when they see more and more companies in the industry adopting the integration technologies to solve the technical difficulties caused by the incompatibility of systems, especially if it is their business partners, competitors or larger trading partners. Thus, telecommunication firms will feel under pressure to adapt to the AI integrated environment to remain competitive (Dasgupta \& Gupta, 2009; Ramdani et al., 2009). In this regard, Sumner, (2000) argue that competitive pressure is a driving force for technology innovation, and the adoption of new technology, or enhancement of existing one, is often a strategic necessity to compete in the marketplace.

\subsection{Empirical Review}

Chen (2019) investigated success factors of Artificial Intelligence Adoption of the Chinese Telecom Industry. Using the TOE framework, the study hypothesized that compatibility, relative advantage, complexity, managerial support, technical capability, government involvement, market 
uncertainty, competitive pressure and vendor partnership influence AI adoption. Using a sample of 255 managers and engineers from major four telecom firms, the Structural equation modelling was deployed to analyze the data. It was found that compatibility $(\beta=0.417, \mathrm{p}<.001)$, relative advantage $(\beta=0.157, p<.001)$, managerial support $(\beta=0.206, p=0.002)$ and vendor partnership $(\beta=$ $0.113, p=.004)$ are significantly related to AI adoption; while market uncertainty $(\beta=0.04, p=$ $0.494)$ and competitive pressure $(\beta=0.036, p=.519)$ are not significantly related to AI adoption.

Awa, Ukoha and Emecheta (2016) used the TO-E theoretical framework to study the adoption of ERP solution of SMEs Port Harcourt, Nigeria. Purposive and snow ball sampling was adopted to arrive at a sampling frame of 373 owners and executives. Model was tested using logistic regression. The hypothesized relationships were supported as results reported Nagelkerke $R^{2}$ of 0.456 , -2 Logistic likelihood $=99.400$, and $p<0.01$ or 0.05 . Specifically, external support $(\beta=-0.480, \mathrm{p}=$ $\left.0.041^{* *}\right)$ and competitive pressure $(\beta=-0.495, \mathrm{p}=$ $\left.0.067^{*}\right)$ had moderate, non-significant negative relationship with adoption of ERP solution.

Savoury (2019) investigated the relationship between relative advantage, complexity, compatibility, technology readiness, top management support, firm size, competitive pressure, and regulatory support and IT leaders' intent to adopt Internet of Things in U.S. manufacturing organizations. A sample of 168 information technology (IT) leaders participated in the study. Multiple regression analysis indicated significant relationships between the intent to adopt Internet of Things and technology readiness $(\beta=.41, \mathrm{p}<.004)$, top management support $(\beta=.29, \mathrm{p}<.034)$ and competitive pressure $(\beta=.33, p<.016)$. The model was able to predict approximately $44 \%$ of the variation of IT leaders' intent to adopt Internet of Things.

Achieng and Jagero (2014) empirically investigated the role of management support in adoption of computer integrated model in financial forecasting of Small and Medium enterprises in Kisumu East District of Kenya. Using a sample of 310 from 1,564 SMEs, data were analyzed with the Pearson's (r) product moment correlation coefficient, via the Statistical Package for Social Sciences (SPSS) version 22. It was found that Managerial Support readiness is positively correlated $(p<0.05)$ with adoption of computer integrated model.

\section{METHODOLOGY}

\subsection{Population and Data Collection Method}

The population comprises four dominant mobile telecommunications firms, namely: MTN, AIRTEL, GLOBACOM and 9MOBILE. The researcher contacted a key informant of The
Association of Telecommunications Companies of Nigeria (ATCON) at Plot 1, Block 99, Olori Muyibat Oyefusi Street, Lekki, Lagos, to get the total number of target respondents from the selected telecos. A total of 1,638 representatives were declared by the telecos, comprising managers (administration/operations/project

managers/marketing), network engineers, heads of IT customer experience and data analysts in selected firms. Thus, the instrument was administered through survey monkey (Waclawski, 2012) via email addresses made available by the telecommunication firms. At the end of the survey, 141 responses were obtained and the information was downloaded into an Excel .csv file, and exported to the Statistical Package for Social Sciences and SmartPLs 3.2.9 software.

\subsection{Questionnaire Design and Operational Measures}

The questionnaire has three sections. Section A contains seven items concerning demographic information of the respondents (e.g., gender, age, marital status). Section B has 6 indicators on Artificial Intelligence Capability, which were developed from the extant work of Qi et al., (2007), Bataller and Harris, (2018) and Kaplan \& Haenlein (2019). Sample item is: "Our systems are continuously self-organizing and perform optimally by learning from network success and failure".

Section $\mathrm{C}$ has five items for Vendor Partnership (Han et al, 2008; Zhu et al., 2003), five items for Managerial Support (Garrison et al., 2015) and three items for Competitive pressure (Chang et al., 2006).

An indicator of Vendor Partnership is "We have had no difficulty in obtaining assistance or reliable services from our vendors/partners"; one of the items of Managerial Support is "the managers explicitly demonstrate support for the adoption of AI through budgetary provisions"; while a sample indicator for Competitive pressure is "Competition due to price war is tough in our industry". Apart from the demographic variables, all other items in the survey instrument were anchored on a five-point Likert scale of $1=$ Strongly Disagree to $5=$ Strongly Agree.

\subsection{Data analysis Techniques}

Demographic data were analysed and reported in frequencies and percent. Mean and standard deviation were observed to ascertain the prevalence of the study phenomena. Skewness and kurtosis were also computed to check normality. All the above aspects were analysed with the aid of the Statistical Package for Social Science (SPSS) version 22. Moreover, the Partial Least Square- Structural Equation Modeling was used to test the psychometric properties of the instrument, as well as the hypotheses. Partial Least Square- Structural Equation Modeling is widely used across several disciplines such as information systems research (Marcoulides \& Saunders, 2006), strategic management and 
marketing (Hair et al., 2012), and beyond. Its ability to model both factors and composites is appreciated by researchers, and makes it a promising method particularly for new technology research and information systems research. Specifically, it has the advantage of placing minimal demand on sample size or normality of data (Fornell \& Bookstein, 1982). Moreover, PLS-SEM can estimate multiple hypothesized effects (Sarkar, Echambadi, \& Harrison, 2001) and maintains robustness even when data are ordinal in nature (Hair Jr., Babin \& Krey, 2017).

\section{DATA ANALYSIS, RESULTS AND DISCUSSION}

\subsection{Demographic Characteristics of respondents}

At the end of the survey, 141 responses (from managers, network engineers, unit heads and data analysts) were obtained and the information was downloaded into an Excel .csv file, and exported to the Statistical Package for Social Sciences and SmartPLs 3.2.9 software. Table 4.1 below shows the demographic characteristics of the respondents.

Table 4.1: Demographic characteristics of Respondents

\begin{tabular}{|c|c|c|c|c|c|}
\hline & & Frequency & Percent & $\begin{array}{l}\text { Valid } \\
\text { Percent }\end{array}$ & $\begin{array}{c}\text { Cumulative } \\
\text { Percent }\end{array}$ \\
\hline \multirow{3}{*}{ GENDER } & Male & 116 & 82.3 & 82.3 & 82.3 \\
\hline & Female & 25 & 17.7 & 17.7 & 100.0 \\
\hline & Total & 141 & 100.0 & 100.0 & \\
\hline \multirow{4}{*}{ AGE } & $20-35$ & 42 & 29.8 & 29.8 & 29.8 \\
\hline & $36-50$ & 89 & 63.1 & 63.1 & 92.9 \\
\hline & $51-$ Above & 10 & 7.1 & 7.1 & 100.0 \\
\hline & Total & 141 & 100.0 & 100.0 & \\
\hline \multirow{5}{*}{$\begin{array}{l}\text { MARITAL } \\
\text { STATUS }\end{array}$} & Single & 19 & 13.5 & 13.5 & 13.5 \\
\hline & Married & 98 & 69.5 & 69.5 & 83.0 \\
\hline & Separated & 20 & 14.2 & 14.2 & 97.2 \\
\hline & Divorced & 4 & 2.8 & 2.8 & 2.8 \\
\hline & Total & 141 & 100.0 & 100.0 & \\
\hline \multirow{4}{*}{$\begin{array}{l}\text { EDUCATIONAL } \\
\text { LEVEL }\end{array}$} & WAEC-OND & 6 & 4.3 & 4.3 & 4.3 \\
\hline & HND/B.SC & 85 & 60.2 & 60.2 & 64.5 \\
\hline & $\begin{array}{l}\text { Masters } \\
\text { Above }\end{array}$ & 50 & 35.5 & 35.5 & 100.0 \\
\hline & Total & 141 & 100.0 & 100.0 & \\
\hline \multirow{5}{*}{ POSITION } & Managers & 16 & 11.3 & 11.3 & 11.3 \\
\hline & $\begin{array}{l}\text { Network } \\
\text { Engineers }\end{array}$ & 63 & 44.7 & 44.7 & 56.0 \\
\hline & Unit Heads & 35 & 24.8 & 24.8 & 80.8 . \\
\hline & $\begin{array}{l}\text { Data } \\
\text { Analysts }\end{array}$ & 27 & 19.2 & 19.2 & 100.0 \\
\hline & Total & 141 & 100.0 & 100.0 & \\
\hline
\end{tabular}

Source: Research Data (SPSS Output), 2020.

Table 4.1 indicates the demographic details of the 141 respondents that participated in the study. For gender distribution, result shows that 116 respondents $(82.3 \%)$ were males while $25(17.7 \%)$ were females. Thus, the industry has more than three quarters of its employees as males. For age distribution, respondents within 36-50 age brackets were in majority with 89 respondents $(63.1 \%)$, while those who are 51years and above were the minority recording $10(7.1 \%)$, and those who are between the age bracket of $20-35$ were 42 which represent $29.8 \%$ of the total number of respondents. Hence, more than three fifths of the employees in the industry are within the age bracket of 36-50. For marital status, 98 respondents $(69.5 \%)$ were married, $19(13.5 \%)$ were single, $20(14.2 \%)$ were separated, while $4(2.8 \%)$ were divorced. This implies that about two thirds of employees in the telecom industry are married. On highest level of educational attainment, 85 respondents $(60.2 \%)$ have Higher National Diploma and Bachelor Degree, 50 respondents (35.5\%) have Master Degree and above, while 6 respondents (4.3\%) have The West African School Certificate and Ordinary National Diploma. Thus, nearly all employees in the industry have diploma and above. Moreover, with respect to position in the organisation, there are 63 network managers, representing $44.7 \%$ of the total number of respondents, $35(24.8 \%)$ unit heads, $27(17.2 \%)$ data Analysts and $16(11.3 \%)$ managers. It means that over three fifths of the employees in the telecommunication industry are network engineers and technical staff. 


\section{2: Univariate Analysis}

The preponderance of the variables in the industry is observed by their means, while normality and kurtosis are used to establish normality of the data distribution. On a five-point scale, mean values (M) between $1.0-2.4 .0=$ low, $2.5-3.4=$ moderate,
$3.5-4.4=$ high; and 4.5 = very high (Asawo, 2009). Moreover, values for skewness $\left(\mathrm{S}_{\mathrm{k}}\right)$ and kurtosis $(\mathrm{Ku})$ between -2 and +2 are considered acceptable in order to prove normal univariate distribution (George \& Mallery, 2010; Gravetter \& Wallnau, 2014). Results for mean, kurtosis and skewness of the data are shown in Table 4.2.

Table 4.17: Descriptive Statistics on the Variables

\begin{tabular}{|c|c|c|c|c|c|c|c|c|c|}
\hline \multirow{2}{*}{ Variable } & & Min & Max & Mean & $\begin{array}{c}\text { Std. } \\
\text { Deviation }\end{array}$ & \multicolumn{2}{|c|}{ Skewness (Sk) } & \multicolumn{2}{c|}{ Kurtosis (Ku) } \\
\cline { 2 - 11 } & Stat. & Stat. & Stat. & Stat. & Stat. & Stat. & $\begin{array}{c}\text { Std. } \\
\text { Error }\end{array}$ & Stat. & $\begin{array}{c}\text { Std. } \\
\text { Error }\end{array}$ \\
\hline VP & 141 & 1 & 4 & 2.57 & .813 & 1.159 & .132 & 1.721 & .533 \\
\hline MS & 141 & 1 & 4 & 2.38 & .588 & - & 1.59 & 1.471 & .492 \\
\hline CP & 141 & 1 & 4 & 2.11 & .837 & 1.280 & .198 & .953 & .418 \\
\hline AIC & 141 & 1 & 4 & 2.52 & .694 & -.982 & .223 & .1543 & .279 \\
\hline
\end{tabular}

Source: Research Data (SPSS Output), 2020

Table 4.2 shows that vendor partnership manifests moderately in the industry $(M=2.57, \mathrm{SD}=$ $0.813)$, managerial support is low $(M=2.38, S D=$ $0.588)$, competitive pressure is low $(M=2.11, S D=$ $0.837)$, while artificial intelligence capability is moderate $(M=3.89, S D=0.71)$.

Moreover, all the latent variables fall within the threshold for normality $( \pm 2.00)$. The highest score for asymmetry was recorded on Competitive Pressure $\left(S_{k}=1.280\right.$, Std. Error $\left.=0.198\right)$, while Vendor Partnership recorded the highest kurtosis score $(\mathrm{Ku}=1.721$, Std. Error $=0.533)$.

Furthermore, there is no need to do more tests on normality since PLS-SEM can substitute for nonparametric approaches as it poses fewer restrictions, especially on data distribution and sample size (Esposito Vinzi, Trinchera \& Amato, 2010).

\section{3: Multivariate Analysis}

\subsection{1: Model Specification}

The PLS model has two layers. The outer model shows how the indicators measure their underlying constructs, while the inner model shows how the variables interact among themselves. This study has three exogenous variables (vendor partnership, managerial support and competitive pressure) and one endogenous variable (artificial intelligence capability). Specifically, this section contains the analysis of how variation in artificial intelligence capability is explained by the combined effect of vendor partnership, managerial support, in the presence of competitive pressure.

Moreover, on sample size criterion, Barclay, Higgins \& Thompson (1995) gave a "10-times rule" that PLS-SEM analysis can be run if the number of cases is not less than 10 times the largest number of structural paths directed at a particular construct in the model. In this study, there are is a maximum of 2 structural paths pointing at the endogenous artificial intelligence capability, which requires a minimum sample size of 52. Since this study has a sample size of 141 , it is suitable to deploy the PLS-SEM.

\subsection{2: Measurement Model}

The data was exported from the SPSS software to SmartPLS 3.2.9 to assess the measurement model. The measurement model output for item reliability, convergent validity (indicated by Average Variance Extracted) and construct reliability is shown in table 4.1: 
Table 4.1: Measurement Model Output

\begin{tabular}{|c|c|c|c|c|c|c|c|}
\hline \multirow{3}{*}{$\begin{array}{c}\text { Latent } \\
\text { Variabl } \\
\text { e }\end{array}$} & \multirow{3}{*}{$\begin{array}{l}\text { Indicator } \\
\quad s\end{array}$} & \multicolumn{3}{|c|}{ Convergent validity } & \multicolumn{3}{|c|}{ Internal consistency reliability } \\
\hline & & Loadings & $\begin{array}{c}\text { Indicator } \\
\text { reliabilit } \\
\mathbf{y} \\
\end{array}$ & AVE & $\begin{array}{c}\text { Composite } \\
\text { reliability }(\rho c) \text { or } \\
\text { RhoA } \\
\end{array}$ & $\begin{array}{c}\text { Reliability } \\
\text { Coefficient } \\
\rho A \\
\end{array}$ & $\begin{array}{c}\text { Cronbach's } \\
\text { alpha (CA) } \\
\text { or } \propto \\
\end{array}$ \\
\hline & & $>0.70$ & $>0.50$ & $>0.50$ & $>0.70$ & $>0.70$ & $0.70-0.90$ \\
\hline \multirow{5}{*}{ VP } & VP_1 & 0.783 & 0.613 & \multirow{5}{*}{0.625} & \multirow{5}{*}{0.901} & \multirow{5}{*}{0.864} & \multirow{5}{*}{0.859} \\
\hline & VP_2 & 0.824 & 0.679 & & & & \\
\hline & VP_3 & 0.777 & 0.604 & & & & \\
\hline & VP_4 & 0.810 & 0.656 & & & & \\
\hline & VP_5 & 0.756 & 0.572 & & & & \\
\hline \multirow{5}{*}{ MS } & MS_1 & 0.764 & 0.584 & \multirow{5}{*}{0.599} & \multirow{5}{*}{0.868} & \multirow{5}{*}{0.841} & \multirow{5}{*}{0.837} \\
\hline & MS_2 & 0.802 & 0.643 & & & & \\
\hline & MS_3 & 0.833 & 0.694 & & & & \\
\hline & MS_4 & 0.746 & 0.557 & & & & \\
\hline & MS_5 & 0.719 & 0.517 & & & & \\
\hline \multirow{3}{*}{$\mathbf{C P}$} & CP_1 & 0.822 & 0.676 & \multirow[b]{3}{*}{0.621} & \multirow[b]{3}{*}{0.875} & \multirow[b]{3}{*}{0.803} & \multirow[b]{3}{*}{0.798} \\
\hline & CP_2 & 0.775 & 0.601 & & & & \\
\hline & CP_3 & 0.765 & 0.585 & & & & \\
\hline \multirow{6}{*}{ AIC } & AIC_1 & 0.827 & 0.684 & \multirow{6}{*}{0.636} & \multirow{6}{*}{0.905} & \multirow{6}{*}{0.893} & \multirow{6}{*}{0.888} \\
\hline & AIC_2 & 0.747 & 0.558 & & & & \\
\hline & AIC_3 & 0.859 & 0.738 & & & & \\
\hline & AIC_4 & 0.807 & 0.651 & & & & \\
\hline & AIC_5 & 0.734 & 0.539 & & & & \\
\hline & AIC_6 & 0.803 & 0.645 & & & & \\
\hline \multicolumn{8}{|c|}{$\begin{array}{c}\text { Note: } \mathrm{VP}=\text { Vendor Partnership, } \mathrm{MS}=\text { Managerial Support, } \mathrm{CP}=\text { Competitive Pressure, } \mathrm{AIC}=\text { Artificial } \\
\text { Intelligence Capability. }\end{array}$} \\
\hline
\end{tabular}

Table 4.1 reveals that all the factor loadings of the overall model scored above the 0.7 cut-off, ranging from 0.719 (MS_5) to 0.859 (AIC_3).The reliability values of the indicators are also above the acceptable 0.50 threshold (MS_5 $=0.517$ to AIC $3=$ 0.738). Thus all the latent variables accounted for more than half of the explained variance in each indicator.

Moreover, the model also satisfied the homogeneity threshold (J"oreskog's rho $A$ or DillonGoldstein's $\rho c>0.7$ ) threshold Next is the evaluation of Dillon-Goldstein's $\rho c$ (or J“oreskog's rhoA) (Wertzetal.1974). This proves composite reliability of the model, with the lowest being 0.868 (Managerial Support), while the highest is 0.905 (Artificial Intelligence Capability). Thus the composite model estimates the true score variance by more than 70\% (Wang \& Stanley, 1970).

Also, the latent constructs scored reliability coefficient (Dijkstra-Henseler's $\rho_{\mathrm{A}}$ ) and Cronbach's (1951)alpha $(\propto)$ values above the 0.7 threshold (Nunnally \& Bernstein, 994). Thus, all the blocks are considered homogenous and the indicators are consistently reasonable in explaining the variances within the model.

\subsubsection{1: Construct Validity}

The next step is the measurement of factors to ascertain if they are free from systematic measurement error. This is simply the quest for validity. Validity comprises convergent and discriminant validity. It is a measure of the average inter-correlations among the indicators that describe a particular construct or LV (Taylor \& Hunter, 2003). An AVE threshold level of 0.5 is an evidence of communality or convergent validity (Fornell \& Larcker, 1981; Bagozzi \& Yi, 1988; Taylor \& Hunter, 2003).

Discriminant validity is proven when each measurement item correlates weakly with all other constructs except for the one to which it is theoretically associated." (Gefen \& Straub, 2005, p.92). This study adopts the Heterotrait-Monotrait (HTMT) ratio of correlations (Wong, 2019) to evaluate discriminant validity. The HTMT is the mean value of the item correlations across constructs relative to the (geometric) mean of the average correlations for the items measuring the same construct (Henseler et al., 2015). HTMT value above 0.85 would suggest that discriminant validity problem is present (Franke \& Sarstedt, 2019). In addition, the HTMT inference is also conducted through bootstrapping. In this case, discriminant validity is established if the confidence interval does not show a value of 1 on any of the constructs (Henseler et al., 2015).

Results for test of convergent and discriminant validity are shown in Table 4.2 . 
Table 4.2: AVE and Heterotrait-Monotrait ratio (HTMT) of the correlations

\begin{tabular}{|c|c|c|c|c|c|}
\hline INDICATORS & AVE & VP & MS & $\mathbf{C P}$ & AIC \\
\hline VP & 0.625 & & & & \\
\hline MS & 0.599 & $\begin{array}{l}0.492 \\
\text { CI [0.258;0.507] }\end{array}$ & & & \\
\hline $\mathrm{CP}$ & 0.621 & $\begin{array}{l}0.481 \\
\text { CI }[0.526 ; 0.731]\end{array}$ & $\begin{array}{l}0.497 \\
\text { CI }[0.235 ; 0.484]\end{array}$ & & \\
\hline AIC & 0.636 & $\begin{array}{l}0.303 \\
\text { CI }[0.310 ; 0.527]\end{array}$ & $\begin{array}{l}0.444 \\
\text { CI }[0.084 ; 0.177]\end{array}$ & $\begin{array}{l}0.518 \\
\text { CI }[0.391 ; 0.630]\end{array}$ & \\
\hline
\end{tabular}

Note: VP = Vendor Partnership, MS = Managerial Support, $\mathrm{CP}=$ Competitive Pressure, AIC = Artificial Intelligence Capability.

Source: SmartPLS 3.2.6 output on research data, 2020.

Following Table 4.2, that all the latent constructs have AVE values higher than the $50 \%$ cut off, ranging from Managerial Support (59.9\%) to Artificial Intelligence Capability (63.6\%). Thus, the model has evidence of convergent validity.

Furthermore, the HTMT values fall below 0.85 thereby fulfilling the criterion of HTMT. 85 (Kline, 2011). Besides, the result of statistical

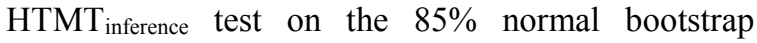
confidence interval, with a Bonferroni adjustment, does not include the value one on any of the constructs (Henseler et al., 2015). This reflects a sufficient and adequate discriminability of the four constructs.

\subsubsection{2: Test of Goodness of Fit (GoF)}

Essentially, GoF reveals whether there is a deviation between the "observed" or "approximated" values of the dependent variable and the values predicted by the PLS model (Dijkstra \& Henseler, 2014). A well-fitted model is one that does not have a misspecification of measurement (Wong, 2019). Fit indices are the Maximum Likelihood discrepancy, the Geodesic discrepancy d_G, the Unweighted Least Squares discrepancy d_ULS, and the Standardized Root Mean Squared Residual (SRMR) approach (Dijkstra \& Henseler, 2015; Henseler, Hubona \& Ray, 2016). This study uses the SRMR which measures the mean absolute correlation residual - the overall difference between the observed and predicted correlations. A Standardized Root Mean Squared Residual (SRMR) not greater than 0.08 signifies acceptable model fit Henseler et al. (2016).

Table 4.3 shows the goodness of fit summary of the hypothesized model.

Table 4.3: Model fit summary

\begin{tabular}{|c|c|c|}
\hline & Saturated Model & Estimated Model \\
\hline SRMR & 0.051 & 0.051 \\
\hline d_ULS & 0.688 & 0.688 \\
\hline d_G & 0.324 & 0.324 \\
\hline Chi-Square & 620.342 & 620.342 \\
\hline NFI & 0.731 & 0.731 \\
\hline
\end{tabular}

Source: SmartPLS 3.2.6 output on research data, 2020

The "Estimated Model" in table 4.3 shows an SRMR value of 0.051 , which is favourable based on the 0.08 threshold. This suggests a good theoretical model fit.

From the assessment of measurement model, it is clear that both reliability and validity have been established for the constructs. Since the measurement model is of sufficient quality, analysis can now graduate to the structural model (Müller, Schuberth $\&$ Henseler, 2018). It is after evaluating the structural model that any conclusion can be drawn.

\subsection{3: Evaluation of the Structural (Inner) Model}

This stage is about the testing of hypotheses. It involves the assessment of path coefficients $(\beta)$ and their significance values; evaluation of predictive accuracy (coefficient of determination) denoted by $R^{2}$; test of predictive relevance or Stone-Geisser's (Geisser 1975; Stone 1974) test, denoted by $\left(Q^{2}\right)$; evaluation of Cohen's (1988) effect size indicated by $f$; and the test of moderating effect (Becker, Ringle, \& Sarstedt, 2018).

\subsubsection{1: Tests of Hypotheses and significance of Structural Path}

Test of hypotheses involves the evaluating the path coefficients ( $\beta$ values), which are essentially standardized regression coefficients assessed in terms of sign, magnitude, and significance. Beta values range from -1 to +1 . Weights closest to absolute 1 reflect the strongest paths. Weights closest to 0 reflect the weakest paths. 
Cohen (1988) specified $\beta$ thresholds of .10 to $0.29, .30$ to .49 and .50 to 1.0 as weak, moderate and strong correlations, respectively. Moreover, for a two tailed test, $t$ values that exceed 1.96 are significant (i.e. unlikely to purely result from sampling error), while $t$ values below 1.96 are non-significant (Hair et al., 2014).
This study bootstrapped 500 samples from the primary sample of 323 using random replacement method. The path coefficients and corresponding $t$ values were observed, thus providing evidence for accepting or rejecting the null hypotheses. Table 4.4 shows the $\beta$ - and $t$ - values of the two main hypotheses $\left(\mathrm{H}_{\mathrm{O} 1}-\mathrm{H}_{\mathrm{O} 2}\right)$, while hypotheses $\mathrm{H}_{3 \mathrm{a}}$ and $\mathrm{H}_{3 \mathrm{a}}$ are tested in subsequent section.

Table 4.4: Results of Hypotheses Testing

\begin{tabular}{|c|c|c|c|c|c|c|}
\hline $\begin{array}{c}\text { Null } \\
\text { Hypothesis }\end{array}$ & $\begin{array}{c}\text { Path } \\
\text { (Relationship) }\end{array}$ & $\begin{array}{c}\text { Path } \\
\text { Coefficient } \\
(\boldsymbol{\beta})\end{array}$ & $\begin{array}{c}\text { Standard } \\
\text { Deviation }\end{array}$ & t-Statistic & P Values & Decision \\
\hline $\mathrm{H}_{01}:$ & VP -> AIC & 0.487 & 0.072 & 2.104 & 0.000 & Rejected \\
\hline $\mathrm{H}_{02}:$ & MS-> AIC & 0.415 & $0.06 \mathrm{I}$ & 1.976 & 0.023 & Rejected \\
\hline $\mathrm{H}_{03} \mathrm{a}:$ & $\mathrm{CP}->$ AIC & 0.251 & 0.057 & 1.872 & 0.000 & Accepted \\
\hline Note: VP = Vendor Partnership, MS = Managerial Support, CP= Competitive Pressure, AIC = Artificial \\
Intelligence Capability. T-statistic greater than 1.96 at 0.05\% level of significance. \\
\hline
\end{tabular}

Source: SmartPLS 3.2.6 output on research data, 2020.

Table 4.4 reveals a moderate, positive and significant path coefficient between VP and AIC $(\beta=$ $0.487, t=2.104)$; a moderate, positive and significant path coefficient between MS and AIC $(\beta=0.415, t=$ $1.976)$; and a weak, positive and non-significant path coefficient between $\mathrm{CP}$ and AIC $(\beta=0.251, t=$ 1.872). $\mathrm{H}_{\mathrm{O} 1}, \mathrm{H}_{\mathrm{O} 2}$ were rejected, while $\mathrm{H}_{\mathrm{O} 3 \mathrm{a}}$ was confirmed.

Thus, there is a partial proof that vendor partnership and managerial support have positive influence on artificial intelligence capability, whereas competitive pressure does not. Going by the $\beta$ values, the model partially suggests that "Vendor Partnership" is the most important driver for artificial intelligence capability while the least important is "Competitive Pressure"

\subsubsection{2: Assessment of Predictive Accuracy $\left(R^{2}\right)$}

The R-squared $\left(R^{2}\right)$ is assessed to ascertain the predictive (practical) accuracy of the exogenous variables in the model. It indicates the combined percent of variability accounted for by the precursor exogenous constructs in the model (Hair et al., 2014). Moreover, the $R^{2}$ a predictive tool which ranges from 0 to 1 , with 1 representing perfect predictive accuracy (ibid). As a very rough guide, $R^{2}$ values of $0.25,0.50$, and 0.75 represent weak, moderate, and substantial levels (Hair et al., 2017). However, Falk and Miller (1992) suggest that $R^{2}$ that is greater than 0.1 should be accepted. Furthermore, an adjusted $R^{2}$ is observed as a check to the exuberance of the $R^{2}$ in overestimating models that have inconsequential variables. As a more conservative measure, the value of $R^{2}$-adjusted is less than (or not more than) the original $R^{2}$.

Table 4.4 show the PLS-SEM output from the bootstrapping procedures to determine the $R^{2}$ Adjusted $R^{2}$ values of the endogenous latent variable.

Table 4.4: Results of Predictive Accuracy $\left(R^{2}\right)$

\begin{tabular}{|c|c|c|c|c|c|}
\hline $\begin{array}{c}\text { Endogenous Latent } \\
\text { Variable }\end{array}$ & $\begin{array}{c}\text { Predictive } \\
\text { Accuracy }\left(\boldsymbol{R}^{2}\right)\end{array}$ & Adjusted $\boldsymbol{R}^{\mathbf{2}}$ & $\begin{array}{c}\text { Standard } \\
\text { Deviation }\end{array}$ & $\boldsymbol{t}$-Statistic & P Value \\
\hline AIC & 0.403 & 0.412 & 0.057 & 2.445 & 0.015 \\
\hline
\end{tabular}

Source: SmartPLS 3.2.6 output on research data, 2020.

Table 4.4 reported model's predictivity $\left(R^{2}\right)$ of 0.403 for artificial intelligence capability. Following the threshold conditions by Chin (1988), the model suggests a weak combined predictability, reaching an explained variance of $40.3 \%$. Despite this weakness, the explained variation of the endogenous constructs meets Falk and Miller's (1992) rule of 0.1(10\%).

This implies that a little higher than two-fifths of artificial intelligence capability level score variance is jointly explained by Vendor Partnership and Managerial Support, while other unidentified variables are responsible for about three-fifths of the variance in artificial intelligence capability. Thus, it is obvious that more variables have to be considered to increase the explanatory power of the model, after establishing a theoretical basis. Next is the assessment of the predictive relevance $\left(Q^{2}\right)$ of the model. 


\subsubsection{3: Assessment of Predictive Relevance $\left(Q^{2}\right)$}

Predictive relevance $\left(Q^{2}\right)$, otherwise called Stone-Geisser test, is an assessment of model fit that indicates how much the model approaches what was expected of it. Q-squared is computed via the sample re-use procedure known as "blindfolding" (Tenenhaus et al. 2005), to arrive at estimates of residual variances, with omission distance set between 5 and 10, where the number of observations divided by the omission distance is not an integer
(Hair et al. 2014). A model with perfect predictive relevance is that which has $Q^{2}$ value of 1 , suggesting it has no errors or perfectly reflects reality. As criteria of evaluation, a model exhibits predictive relevance if $Q^{2}$ value greater than zero is obtained (Hair et al., 2014). Table 4.5 shows the output for a crossvalidated predictive relevance through blindfolding with an omission distance of 7 .

Table 4.5: Construct Cross-validated Redundance (Total $Q^{2}$ )

\begin{tabular}{|c|c|c|c|}
\hline Endogenous Latent Variable & SSO & SSE & $\mathrm{Q}^{2}=\mathbf{1}$-SSE/SSO \\
\hline VP & 1549.000 & 1549.000 & \\
\hline MS & 1549.000 & 1549.000 & \\
\hline CP & 1549.000 & 1278.629 & 0.175 \\
\hline \multicolumn{2}{|l|}{$\begin{array}{l}\mathrm{Q}^{2}=\text { Predictive Relevance; SSE= sum of squares of prediction errors; SSO = sum of squares of } \\
\text { observations. Reference values: } \mathrm{Q}^{2}>0 \text { = satisfactory predictive relevance, Hair et al., 2011. }\end{array}$} \\
Source: SmartPLS 3.2.6 output on research data, 2020.
\end{tabular}

Following table 4.5, the bundle of exogenous latent variables present an acceptable cross-validated redundancy index $\left(Q^{2}=0.175>0\right)$. This means that the path model predicts the originally observed values very well.

\subsubsection{4: Test of Moderating Effect}

This section is dedicated to the test of hypotheses $\mathrm{H}_{\mathrm{O} 3 \mathrm{~b}}$ and $\mathrm{H}_{\mathrm{O} 3 \mathrm{c}}$.

Test for moderating effect involves: (i) the identification of the relationship between vendor partnership (VP) and artificial intelligence capability (AIC) in the presence of competitive pressure (CP), and (ii) the identification of the relationship between managerial support (MS) and artificial intelligence capability (AIC) in the presence of competitive pressure $(\mathrm{CP})$. The effect size criterion was deployed to test for moderation.

The formula for effect size of the moderator is given as:

$$
f^{2}=\frac{R_{\text {moderatorpresent }}^{2}-R_{\text {moderatorabsent }}^{2}}{1-R_{\text {moderatorpresent }}^{2}}
$$

Where moderating effects with effect sizes $\left(f^{2}\right)$ of $0.02,0.15$, or above 0.35 can be regarded as low, medium, or high. Less than 0.02 means no effect (Cohen, 1988).

Table 4.7 indicates the effect size of $\mathrm{CP}$ in the $V P \rightarrow A I C$ in the model.

Table 4.7: Effect Size of the moderator (CP) in VP $\rightarrow$ AIC model $\left(\mathrm{H}_{03 \mathrm{~b}}\right)$

\begin{tabular}{|c|c|c|c|c|c|}
\hline $\begin{array}{c}\text { Exogenous } \\
\text { Variable }\end{array}$ & $\begin{array}{c}\text { Endogenous } \\
\text { Variable }\end{array}$ & $\begin{array}{c}\boldsymbol{R}^{\mathbf{2}} \\
\text { with moderator }\end{array}$ & $\begin{array}{c}\boldsymbol{R}^{\mathbf{2}} \\
\text { without } \\
\text { moderator }\end{array}$ & $\begin{array}{c}\boldsymbol{f}^{2} \text {-effect } \\
\text { size }\end{array}$ & $\begin{array}{c}\text { Remark on } \\
\text { Effect Size }\end{array}$ \\
\hline VP & AIC & 0.409 & 0.401 & 0.014 & No effect \\
\hline
\end{tabular}

Source: Manual Calculation based on output from SmartPLS 3.2.9, 2020.

Table 4.7 suggests that competitive pressure has no effect $\left(f^{2}=0.014\right)$ on the relationship between vendor partnership and artificial intelligence capability. Therefore, the hypothesis four $\left(\mathrm{H}_{\mathrm{O}}: 3 b\right)$ which states that "Variation in artificial intelligence capability due to vendor partnership is not significantly a function of competitive pressure." is confirmed.
Next is the test for the moderating effect of competitive pressure on the relationship between managerial support and artificial intelligence capability. Table 4.8 indicates the effect size of CP in the $M S \rightarrow A I C$ in the model.

Table 4.8: Effect Size of the moderator (CP) in $M S \rightarrow A I C$ model $\left(\mathrm{H}_{03 \mathrm{~b}}\right)$

\begin{tabular}{|c|c|c|c|c|c|}
\hline $\begin{array}{c}\text { Exogenous } \\
\text { Variable }\end{array}$ & $\begin{array}{c}\text { Endogenous } \\
\text { Variable }\end{array}$ & $\begin{array}{c}\boldsymbol{R}^{\mathbf{2}} \\
\text { with } \\
\text { moderator }\end{array}$ & $\begin{array}{c}\boldsymbol{R}^{\mathbf{2}} \\
\text { without } \\
\text { moderator }\end{array}$ & $\begin{array}{c}\boldsymbol{f}^{2} \text {-effect } \\
\text { size }\end{array}$ & $\begin{array}{c}\text { Remark on } \\
\text { Effect Size }\end{array}$ \\
\hline MS & AIC & 0.404 & 0.397 & 0.012 & No effect \\
\hline
\end{tabular}


Table 4.8 suggests that competitive pressure has no effect $\left(f^{2}=0.012\right)$ on the relationship between managerial support and artificial intelligence capability. Therefore, the hypothesis four $\left(\mathrm{H}_{\mathrm{O}}: 3 \mathrm{c}\right)$ which states that "Variation in artificial intelligence capability due to managerial support is not significantly a function of competitive pressure" is confirmed.

\section{4: Discussion}

This study empirically investigated the influence of vendor partnership (VP) and managerial support (MS) on Artificial Intelligence Capability (AIC), in the presence of Competitive Pressure (CP). The study was domiciled in the Nigerian telecommunication industry.

The univariate aspect of the analysis reveals that the telecom sector in Nigeria manifests low levels of managerial support and competitive pressure; and moderate levels of vendor partnership and artificial intelligence capability. This suggests that internal processes are below average but the external collaboration is just sufficient. Thus, the result is a pointer that the moderate level of artificial intelligence capability in the industry is, perhaps, traceable more to the synergistic relationship between the firms and vendors, than to the internal support from managers. Moreover, the low level of competitive pressure confirms the oligopolistic climate of the industry.

At the multivariate level of analysis, the first hypothesis was rejected on the grounds that there is a positive and significant relationship between vendor partnership and Artificial Intelligence Capability. This means that higher levels of vendor participation will trigger Artificial Intelligence Capability in the Nigerian telecommunication industry. Thus, when firms step up their collaboration with trustworthy, reliable and knowledgeable vendors in AI-enabled technologies, they stand to harvest organisational benefits evidenced by a surge in the way AI-enabled systems sense, learn, act and self-organize, for effective utilization of network resources. This finding is in harmony with Chen (2019) who concluded that a close relationship between firms and vendors not only fosters the adoption of new technology, but also aids firms to innovate and improve their existing capabilities. The finding also supports the submission made by Stuart (1997) that partnerships promote operational capabilities of participating organizations and to help them achieve significant on-going benefits.

The second hypothesis was rejected since the structural model revealed a positive and significant relationship between managerial support and Artificial Intelligence Capability. This means that if managers provide more support to members, with respect to the deployment of AI-enabled systems, there will be improvement in Artificial Intelligence Capability. Therefore, a culture that creates favourable internal environment for AI-enabled systems through adequate funding, training and cross-functional cooperation and communication will accelerate the extent to which AI-enabled systems easily perceive the business environment, correctly recognize, interpret and contextualize signals, and easily identify the operations area where improvements are expected to affect the customer most. This finding aligns with the separate submissions of Co et al., (1998) and Chen (2019) that Support and commitment from managers is critical in guiding the allocation of resources to activities which improves capabilities (Co et al., 1998). Also, this finding resonates with Savoury's (2019) finding that top management support enhances the IT leaders' intent to orchestrate Internet of Things (IoT), a variant of AI-technology. Moreover, Teo et al. (2009) also found that support from vendors ensures effective implementation, market acceptance and value maximization of technologies.

HypothesisH $_{\mathrm{O}: 3 \mathrm{a}}$ which states that "there is no significant relationship between competitive pressure and Artificial Intelligence Capability" was supported by the data. Similarly, data supported $\mathrm{H}_{\mathrm{O}: 3 \mathrm{~b}}$ which states that "variation in artificial intelligence capability due to vendor partnership is not significantly a function of competitive pressure". Also, $\mathrm{H}_{\mathrm{O}: 3 \mathrm{c}}$ which states that "variation in artificial intelligence capability due to managerial support is not significantly a function of competitive pressure" was accepted, as data indicated non-significance. This indicates that the artificial intelligence capability benefits of vendor collaboration and managerial support have nothing to do (at least, statistically) with competitive forces. Chen (2019) empirically demonstrated that competitive pressure does not have bearing on AI processes. Moreover, the findings on these three hypotheses are in tandem with Awa, Ukoha and Emecheta's (2016) finding that the effective deployment of technological solutions in enterprises is not influenced by pressures from competitors. A possible explanation to these findings is that that the major telecom firms in Nigeria are oligopolistic. Hence, there is no much of competitive pressure among them that warrant increase in vendor partnership and managerial support, in order to harvest higher benefits of artificial intelligence capability.

\section{CONCLUSIONS AND RECOMMENDATIONS}

Numerous studies have established clear and predictable patterns of relationship between internal and external factors, and IT adoption. However, there is scanty literature on that investigated Artificial Intelligence Capability through the lens of environmental and organisational determinants factors. Moreover, this study appears to be first to empirically investigate the dynamic interaction of these constructs in telecommunication firms in a developing country. In addition, this study empirically extends the T-O-E framework (Tornatzky 
\& Fleischer, 1990) to the domain of artificial intelligence in organisations.

The study deployed positivist approach and concludes that vendor partnership and managerial support amplify artificial intelligence capability of telecos in Nigeria; whereas competitive pressure does not buffer the hypothesized relationships.

This implies that managers ought to be aware of the positive effect of the collaboration they have with vendors on the ability to leverage AI artefacts, for greater organisational outcomes. Specifically, there is the need for telecommunication firms to understand that rule of the game lies in the ability to enlist the services of trustworthy, reliable and knowledgeable vendors, in order to orchestrate dynamic and organic AI-enabled systems that easily sense, learn, act and self-organize, for effective utilization of network resources. Moreover, managers should be cognizant of the fact that the capabilities of AI-enabled systems can be accentuated if they create favourable internal environment through adequate funding, training and cross-functional cooperation and communication.

\section{Based on the foregoing, the study recommends that:}

(i) Telecommunication companies Nigeria should improve the quality of partnership with their vendors. Specifically, they should only select partners who are trusted, reliable and knowledgeable in the emerging AI- enabled technologies. Moreover, only partners that share risks and benefits, and support the development of innovative products and processes should be selected. The companies should emphasize lasting, strong and extensive social, economic, commercial and technical ties. Shared commitment and contacts should percolate at different departments such as: marketing, operations, quality control, logistics and finance. Provision, in multiple contexts, should be made to integrate information flow and to have direct and continuous interaction between the firms and their vendors.

(ii) Managers should ensure interrupted support for the improvement of AI-enabled platforms. Specifically, they should nurture a culture in their organisations to enable members adapt to new technologies. Managers should channel resources in such a way that AI-initiatives are adequately funded. They should also design appropriate ways for members to learn the technology. Managers should also managers encourage teams and cross-functional cooperation and communication in the use of AIenabled platforms.

\section{1: Limitations and Suggestions for Future Research Directions}

This study is not inoculated from limitations. The first limitation borders on the cross-sectional nature of the study, whereby the instrument was administered at "one shot". It is possible that participants would respond differently if the same set of questionnaire were administered at various time intervals. Future studies should be longitudinal to capture the dynamic interaction among the variables.

Moreover, the study adopted two variables from the T-O-E framework as promoters of artificial intelligence capability, whereas there are other factors suggested in literature. Thus, future research should test the role of the entire T-O-E framework in the advancement of artificial intelligence capability.

Corporate leaders in other sectors should be cautious of generalizing the findings as this study was restricted telecommunication firms in Nigeria. Thus, researchers may extent the model to other sectors such as manufacturing and banking industry.

Also this study is susceptible to common method bias since self-reported measures were used. Further studies should include some measures, such as test of Common Method Variance, to ascertain the integrity of responses.

Finally, this study is purely positivist and hypotheco-deductive nature. Thus the study did not allow for the collection of qualitative data that gives the researcher the benefit of tapping into the richness and depth of the relationships between the variables. Future studies can collect and simultaneously analyse quantitative and qualitative data, so that the epistemological deficiencies of one method can be compensated by the other, in order to achieve a greater level of ontological integrity.

Despite the aforementioned encumbrances, this study offers a window of understanding for managers, scholars, information technology pundits, governments and industry giants on the interaction between vendor partnership, managerial support, competitive pressure and artificial intelligence capability. The study successfully extends the research frontiers on AI in organisations of developing countries through the lens of TechnologyOrganisation-Environment (T-O-E) framework.

\section{REFERENCES}

1. Akpan, E. E., Ibekwe, U., Worgu, S. C. \& Nwangwu, C. E. (2018). Social media usage and firm performance: Reflections from the Nigerian telecommunication sector. International Journal of Management Science and Business Administration, 4(6), 7-16.

2. Asawo, S. P. (2009). Spiritual leadership and workers' commitment in the Nigerian manufacturing industry. (A PhD thesis submitted in the Department of Management, Faculty of Management Sciences, Rivers State University of Science And Technology, Nkpolu, Oroworukwo, Port Harcourt).

3. Barclay, D., Higgins, C., \& Thompson, R. (1995). The partial least squares (PLS) approach to causal modeling: Personal computer adoption and use as an illustration. Technology Studies, 2(2), 285-309.

4. Baron, R. M.,\& Kenny, D. A. (1986). Moderator-mediator variables distinction in social psychological research: Conceptual, 
strategic, and statistical considerations. Journal of Personality and Social Psychology, 51(6), 1173-82.

5. Becker, J-M., Ringle, C, M., \& Sarstedt, M. (2018). Estimating moderating effects in PLSSEM and PLSC-SEM: Interaction term generation data treatment. Journa/ of Applied Structural Equation Modeling, 2(2), 1-21.

6. Chin, W. W. (1998). The partial least squares approach for structural equation modeling. In G. A. Marcoulides (Ed). Modern methods for business research. 295-336. Lawrence Erlbaum Associates.

7. Cohen, J. (1988). Statistical power analysis for the behavioural sciences. Lawrence Erlbaum.

8. Eisenberger $\mathrm{R}$, Huntington $\mathrm{R}$, Hutchison $\mathrm{S}$, et al. (1986) Perceived organizational support. Journal of Applied Psychology 71(3): 500 507.

9. Esposito Vinzi, V., Trinchera, L., \& Amato, S. (2010). PLS path modelling: From foundations to recent developments and open issues for model assessment and improvement. In $\mathrm{V}$. Esposito Vinzi, W. W. Chin, J. Henseler, \& H. Wang (Eds.), Handbook of partial least squares: Concepts, methods and applications (pp. 47-82). Berlin, Germany: Springer-Verlag.

10. Falk, R. F., \& Miller, N. B. (1992). A primer for soft modeling. University of Akron Press.

11. Fornell, C. \& Bookstein, F. L. (1982). Two structural equation models: LISREL and PLS applied to consumer exit-voice theory. Journal of Marketing Research, 19, 440-452.

12. Fornell, C. \& Larcker, D. F. (1981). Evaluating structural equation models with unobservable variables and measurement error. Journal of Marketing Research, 18 (1), 39-50.

13. Gara ' $a-S a$ 'nchez E, Gara 'a-Morales VJ, Bolt 'var-Ramos MT (2017) The influence of top management support for ICTs on organisational performance through knowledge acquisition, transfer, and utilisation. Rev Manag Sci 11(1):19-51

14. Gefen, D., Straub, D. W. \& Boudreau, M. C. (2000). Structural equation modeling and regression: Guidelines for research practice. Communications of the Association for Information Systems, 4(7), 1-70.

15. Geisser, S. (1975). The predictive sample reuse method with applications. Journal of the American Statistical Association, 70(350) 320328.

16. Hair, J. F., Babin, B. J. \& Krey, N. (2017). Covariance-based structural equation modelling in the journal of advertising: Review and recommendations. Journal of Advertising, 46(1), 163-177.

17. Hair, J. F., Hult, G. T. M., Ringle, C. M. \& Sarstedt, M. (2014). A Primer on partial least squares structural equation modelling. Thousand Oaks, CA: Sage.
18. Hair, J. F., Hult, G. T. M., Ringle, C. M. \& Sarstedt, M. (2017). A primer on partial least squares structural equation modelling (PLSSEM) (2nd Ed). Thousands Oak, CA: Sage Publications.

19. Hair, J. F., Ringle, C. M. \& Sarstedt, M. (2011). PLS-SEM: Indeed a silver bullet. Journal of Marketing Theory and Practice, 19(2), 139151.

20. Hair, J. F., Risher, J. J., Sarstedt, M., \& Ringle, C. M. (2019). When to use and how to report the results of PLS-SEM. European Business Review, 31(1), 2-24.

21. Henseler, J., Ringle, C. M. \& Sinkovics, R. R. (2009). The use of partial least squares path modelling in international marketing. Advances in International Marketing, 20, 277320.

22. Ibekwe, U. J., Agbaeze, E. K., Nwakoby, N. P., Abner, I. P., Kelvin-lloafu, L. E., Akpan, E. E. (2019). Social media adoption and performance of telecommunication firms in Nigeria: From innovation diffussion theory to technology acceptance model. International Journal of Mechanical Engineering and Technology, 10(12), 100-114.

23. Lohmoller, J. B. (1989). Latent variable path modeling with partial least squares. Heidelberg: Physica.

24. Nunnally, J. C.,\& Bernstein, J. H. (1994). Psychometric theory(3rd Ed.).McGraw-Hill.

25. Sarstedt, M., Ringle, C. M., \& Hair, J. F. (2017). Partial least squares structural equation modeling. In $C$. Homburg, $M$. Klarmann, \& A. Vomberg (Eds.). Handbook of market research. 1-40. Heidelberg: Springer.

26. Stone, M. (1974). Cross valedictory choice and assessment of statistical predictions. Journal of the Royal Statistical Society,36(2), 111-147.

27. Streukens, S.,\&Leroi-Werelds, S. (2016). Bootstrapping and PLS-SEM: A step-by-step guide to get more out of your bootstrap results. European Management Journal, 34(6), 618-632.

28. Sylva, W. \& Akpan, E. E. (2016). The impact of structure on strategy implementation among telecommunication firms in Nigeria. European Journal of Business and Management, 8(14), 59-68.

29. Taylor, S. A., \& Hunter, G. L. (2003). The impact of loyalty with e-CRM software and eservices. International Journal of Service Industry Management, 13(5).452-74.

30. Tenenhaus, M., Vinzi, V. E., Chatelin, Y. M. \& Lauro, C. (2005). PLS path modelling. Computational Statistics and Data Analysis, 48(1), 159-205.

31. Tornatzky L, Fleischer M (1990) The process of technology innovation. Lexington Books, Lexington, MA 
32. Wang, M.,\& Stanley, J. (1970). Differential weighting: A review of methods and empirical studies. Review of Educational Research, 40, 663-705.

33. Wold, H. (1982). Soft modeling: The basic design and some extensions. In, Jöreskog,
K.G., Wold, H. (Eds.), Systems under indirect observations: Causality, structure, prediction, Part 2. 1-54. North-Holland, Amsterdam.

APPENDIX 1

A Questionnaire on Determinants of Artificial Intelligence Capability in the Nigerian Telecommunications Industry

\author{
Section A
}

\title{
Personal Data:
}

1. Name of organization

2. Gender: Male $\square$ Female

3. Age: 20-35 $\square 36-50$ 51 Above

4. Marital status: Single Married Separated Divorced

5. Educational Qualification: WAEC-OND $\mathrm{HND} / \mathrm{B} . \mathrm{Sc}$ MSc and above

6. Position in the organization

7. Years of experience in the organization: $0-5 \square$ - $6-10$ 11-Above

\section{Section B}

\section{Artificial Intelligence Capability}

Kindly, indicate the extent to which you agree or disagree that the statement reflects the situation in your organization.

( $1=$ strongly disagree, $2=$ disagree, $3=$ undecided, $4=$ agree, $5=$ strongly agree $)$

\begin{tabular}{|l|l|l|l|l|l|l|}
\hline S/N & $\begin{array}{l}\text { AI Capability (Qi et al., 2007; Bataller \& Harris, 2018; } \\
\text { Kaplan \& Haenlein, 2019) }\end{array}$ & $\mathbf{1}$ & $\mathbf{3}$ & $\mathbf{4}$ & $\mathbf{5}$ \\
\hline 1 & $\begin{array}{l}\text { Our systems easily perceive the business environment and } \\
\text { acquire data like images, speech, and text. }\end{array}$ & & & & \\
\hline 2 & $\begin{array}{l}\text { Our systems correctly recognize, interpret and contextualize } \\
\text { signals. }\end{array}$ & $\begin{array}{l}\text { Routing is adaptive and provided efficient utilization of } \\
\text { network resources in response to changes in the network. }\end{array}$ & & & \\
\hline 3 & $\begin{array}{l}\text { AI application provides security and privacy, detects fraud and } \\
\text { fault, and monitor, diagnose and control network effectively. }\end{array}$ & & & \\
\hline 4 & $\begin{array}{l}\text { Our AI systems take prompt and accurate actions based on their } \\
\text { comprehension of the physical or digital world }\end{array}$ & & & \\
\hline 5 & $\begin{array}{l}\text { Our systems are continuously self-organizing and perform } \\
\text { optimally by learning from network success and failure }\end{array}$ & $\begin{array}{l}\text { Systems easily identify the operations area where } \\
\text { improvements are expected to affect the customer most }\end{array}$ & & & \\
\hline 6 &
\end{tabular}




\section{Section C}

\section{Determinants of Artificial Intelligence Capability}

Kindly, indicate the extent to which you agree or disagree that the statement reflects the situation in your organization.

( $1=$ strongly disagree, $2=$ disagree, $3=$ undecided, 4 =agree, $5=$ strongly agree $)$

\begin{tabular}{|c|c|c|c|c|c|c|}
\hline $\mathbf{S} / \mathbf{N}$ & Vendor Partnership (Han et al, 2008; Zhu et al., 2003) & 1 & 2 & 3 & 4 & 5 \\
\hline 1 & $\begin{array}{l}\text { We have had no difficulty in obtaining assistance or reliable } \\
\text { services from our vendors/partners. }\end{array}$ & & & & & \\
\hline 2 & Our vendors/partners are trustworthy. & & & & & \\
\hline 3 & Vendor makes decisions beneficial to my organization. & & & & & \\
\hline 4 & We have very close relationships with vendors/partners. & & & & & \\
\hline \multirow[t]{2}{*}{5} & Our vendors/partners are knowledgeable for AI technologies & & & & & \\
\hline & Managerial Support (Garrison et al., 2015) & 1 & 2 & 3 & 4 & 5 \\
\hline 1 & $\begin{array}{l}\text { The managers explicitly demonstrate support for the adoption } \\
\text { of AI through budgetary provisions }\end{array}$ & & & & & \\
\hline 2 & $\begin{array}{l}\text { Managers emphasize a culture that nurtures and creates } \\
\text { favourable environment to accept and use latest AI-enabled } \\
\text { systems. }\end{array}$ & & & & & \\
\hline 3 & $\begin{array}{l}\text { Our managers provide training for technical staff to exploit } \\
\text { new technologies before our competitors. }\end{array}$ & & & & & \\
\hline 4 & $\begin{array}{l}\text { Our managers have the ability to leverage new AI technologies } \\
\text { as a strategic core competence }\end{array}$ & & & & & \\
\hline \multirow[t]{2}{*}{5} & $\begin{array}{l}\text { Our managers encourage teams and cross-functional } \\
\text { cooperation and communication in the use of AI-enabled } \\
\text { platforms }\end{array}$ & & & & & \\
\hline & Competitive pressure (Chang et al., 2006) & 1 & 2 & 3 & 4 & 5 \\
\hline 1 & $\begin{array}{l}\text { The rate of innovation of new operating processes and new } \\
\text { products or services in our principal industry has increased } \\
\text { dramatically. }\end{array}$ & & & & & \\
\hline 2 & Competition due to price war is tough in our industry & & & & & \\
\hline 3 & There is high competition on product/service quality & & & & & \\
\hline
\end{tabular}

